\title{
Measuring Poverty and Income Inequality in Australia
}

\section{Peter Whiteford}

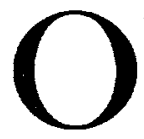

VER the past 20 years the number of income distribution and poverty studies in Australia has increased enormously. Surveys undertaken by the Australian Bureau of Statistics (ABS), particularly the Income Distribution Surveys (IDS) and the Household Expenditure Surveys (HES), contain detailed information on the economic circumstances of households and families.

Yet the literature provides a bewildering array of contradictory results and trends. We hear that there is an ever-rising tide of poverty, that the rich are getting richer and the poor poorer, that the gap between rich and poor is wider than at any time since the $1940 \mathrm{~s}$, that the middle class is shrinking or disappearing (or that there is a 'new middle class'), and that there is an emerging underclass. From supposedly being the wealthiest country in the world at the end of the 19th century, as well as one of the least unequal, Australia is said to be slipping in the national income stakes and to be one of the most unequal developed countries. But we are also told that average incomes and living standards are at a higher level than at any previous time in Australia's history, that the real value of benefits for the poor has increased substantially over time, and that government spending on health, education and other community services ${ }^{1}$ also significantly reduces inequality.

There is no unanimity on either the trend or level of inequality and poverty in Australia. Some authorities conclude that poverty increased by around 60 per cent over the 1980s (Saunders, 1994); others claim that it fell by more than 20 per cent (Harding \& Mitchell, 1992). Often, individual researchers have simply focused on different aspects of income and used differing methods of analysis. Such technical choices can change the direction of measured social trends: for example, some of the technical judgements made in research using the 'Henderson poverty line' are problematic and internally contradictory, thus producing poverty estimates that are potentially misleading.

This article identifies and discusses some of the main technical factors affecting both poverty measurement and distributional analysis.

'Sometimes called the 'social wage' (Harding, 1982).

Peter Whiteford works in the Strategic Planning Division of the Department of Social Security, Canberra. The views expressed are his own and should not be attributed to the Department of Social Security. 


\section{The Concept of Living Standards}

Most distributional studies are concerned with material living standards rather than broader welfare concepts, such as satisfaction with life, levels of security, social isolation, or feelings of stress. But material living standards may rise while many households subjectively feel worse-off. Individuals may work longer hours to produce higher incomes, but feel under pressure. The increased labour-force participation of women may produce higher measured family income, but some individuals may prefer to spend more time with their children.

Some negative factors may not be given a monetary value, such as declining environmental quality. Other positive contributions to material well-being, such as unpaid work in the home, are often ignored. But it is possible to give many factors a monetary value (Travers \& Richardson, 1993).

\section{The Measure of Resources}

The concentration on material living standards reflects the quantitative preferences of researchers. The measure of material resources is probably the most important issue to be considered in any distributional study; yet it often attracts the least discussion.

Consider the differences between the distribution of income and the distribution of expenditures or consumption. According to the 1993-94 HES, the average gross income of the highest income quintile was around eleven times that of the lowest income quintile, but the ratio of the average expenditure of these groups was around 3.3 to 1 . Several factors explain this large difference. High-income groups pay more income tax than low-income groups and save more of their income. Lowincome individuals may run down their savings or go into debt to maintain expenditure levels, while some self-employed have low current incomes or are experiencing business losses. But the difference shows that an appraisal of the level of inequality is highly dependent on the choice of the measure of resources.

Figure 1 sets out the income accounting framework used in most Australian and overseas studies. Most studies treat material standards of living as synonymous with cash incomes. By definition, the more comprehensive the definition of income, the more accurate is the measure of material resources. But no study can be said to use a fully comprehensive definition of income. Some well-known studies concentrate on wage and salary income (Gregory, 1993); others use gross incomes before tax (Gregory \& Hunter, 1995). But the most common measure is after-tax disposable income (Saunders, 1994). Recent work by the National Centre for Social and Economic Planning (NATSEM) (Harding, 1995) includes the value of other social spending on services, but excludes the effects of indirect taxes. Yates (1991) shows the impact of owner-occupied housing on income distribution. The most comprehensive studies are those undertaken by the ABS (1987, 1992, 1996a), which analyse the impact of community services and indirect taxes; but even they do not include private housing wealth, capital gains or fringe benefits. 


\section{Figure 1}

\section{The income-accounting framework}

\begin{tabular}{|lr|}
\hline Wages and salaries plus self-employment income plus property income & factor income \\
\hline plus occupational and private pensions & market income \\
\hline $\begin{array}{l}\text { plus social security cash benefits (universal, income-related, contributory) } \\
\text { plus private transfers plus other cash income }\end{array}$ & gross income \\
\hline minus income tax (and employee social security contributions) & cash disposable income \\
\hline times equivalence scales & equivalent cash disposable income \\
\hline & \\
\hline $\begin{array}{l}\text { Possible additional components: the social wage, indirect taxes, imputed income from } \\
\text { owner-occupied housing, fringe benefits, capital gains }\end{array}$ \\
\hline
\end{tabular}

Many studies deal with only part of total income distribution, legitimately concentrating on specific trends in wage and salary or cash disposable income, for example: But it follows that it is necessary to be cautious about the conclusions drawn from incomplete studies.

The ABS (1996b) has recently published a conceptual framework for statistics on household income, consumption, saving and wealth. Under this framework, economic well-being can be described from a disbursements perspective as the sum of consumption, changes in net worth, and a notional wealth annuity. From a receipts perspective, this is equivalent to net disposable income minus saving, plus the change in net worth and a notional wealth annuity.

It is also notable that virtually all studies that broaden the measure of resources produce lower estimates of poverty and inequality than those that use cash disposable income (Harding, 1995; Smeeding et al., 1992).

\section{The Period of Assessment}

Since individuals may accumulate or withdraw savings, their current living standards are not identical to their current incomes. Their circumstances may change significantly over their lifetime and also within a single year. The pattern of income changes with the family life-cycle. This pattern has changed over the 20 th century and government programs now redistribute resources from times of relative affluence to relative need; but important features of the family life-cycle remain pertinent. This pattern coexists with inequality between classes, but should not be confounded with it.

Individuals also change their family status and therefore their incomes perhaps more frequently than in the past. Still, more people experience a relatively short period of lone parenthood than remain lone parents for five or more years, say. For these and other reasons, differences in the period used in analysis may affect measured income inequality. For example, using the 1990 IDS, it can be estimated that the Gini coefficient for wage and salary income is 0.300 for current income 
data, but 0.352 for the annual data, a very substantial difference of around 17 per

The time horizon used may be particularly significant when measuring the impact of public policy. Creedy (1994) notes that as transfers have an insurance element and a redistributive element, their redistributive element cannot be examined using only annual information. This point is of crucial importance in international comparisons of redistribution, since the mix of self-insurance and actual redistribution differs between countries. Falkingham and Harding (1996), for example, compare the redistributive impact of the UK and Australian social security systems. In the targeted Australian system, 38 per cent of lifetime benefits received by individuals are paid for at another stage in their life (that is, they are equivalent to selfinsurance); the remaining 62 per cent consists of redistribution between income groups. In the UK, in contrast, only 38 per cent of benefits is accounted for redistribution between different income groups. By spending less overall on social security than nearly any other developed country, Australia appears to provide less by way of redistribution between income groups. But this reflects the fact that, in a single year accounting period, it is implicitly assumed that all measured transfer spending consists of redistribution between income groups, when in fact much of it is self-insurance.

One means of correcting this bias is to undertake lifetime incidence studies of income distribution and redistribution (Harding, 1993). An alternative is to bring all public and private redistribution within the compass of a single year's accounting period. This would involve developing a comprehensive measure of income, covering the benefits of all forms of government activity, including imputed wealth in the form of public pension rights, as well as the costs and benefits of private provision, such as imputed income from owner-occupied housing (Yates, 1991).

\section{The Income Sharing Unit}

While we are all individuals, we also live in households that may contain other people with whom we may share income or expenses. We are also members of families who may share resources even when we do not live in the same households, and we provide gifts and other voluntary transfers to other households. On the other hand, young adults may live at home, but have a degree of independence in managing their incomes.

Most studies assume that couples completely share their incomes between themselves and their dependent children. Actual income sharing is unmeasured, however, and the equal-sharing assumption has been questioned. Even where patterns of income sharing differ, household members who share may face lower

2 3

The Gini coefficient ranges between 0 and 1 with a higher Gini implying greater inequality.

For example, assume that Australia spent 10 per cent of GDP on transfers, while the UK spent 15 per cent of GDP. If we separate out the redistributive and self-insurance components, then Australian redistribution would be 6.2 per cent of GDP, while UK redistribution is 5.7 per cent of GDP. So, contrary to the standard approach, actual redistribution would be greater in Australia than in the UK. 
housing and related costs than they would if living separately. Consequently, studies must decide whether income is measured for individuals alone, for the nuclear family, for the extended family or for the household. Results will differ depending on the choice made, which must be arbitrary to the extent that the actual degree of income sharing within households and between related individuals is unknown. In general terms, the wider is the unit assumed to share resources, the lower will be the level of measured inequality or poverty.

\section{Equivalence Scales}

Equivalence scales seek to quantify the relative incomes needed by different types of families to attain similar living standards. They are usually expressed as a set of numbers with some family type chosen as the base. Fixing the scale for a single person at 60 per cent of that of a couple without children implies that a single person with an income of $\$ 12,000$ is as well off as a couple without children and an income of $\$ 20,000$.

Given a set of scales, researchers adjust actual income by the scale to produce a measure of 'equivalent income'. This re-ranks households, so that smaller households have their income adjusted upwards and larger households have their incomes adjusted downwards to reflect the estimated relationship between needs and income.

No consensus exists on the appropriate method of estimation; and empirical estimates of scales vary widely (Whiteford, 1985). However, the social security system contains a set of implicit equivalence scales that strongly affect the relative incomes of households (mainly age pensioners and sole parents) where many people rely entirely on benefits. This concentration of households around statutory benefit levels means that slight variations in the scales used may result in either a very high or a very low proportion of these populations estimated to be in poverty. The use of different equivalence scales may therefore have a substantial impact on estimates of the extent of inequality and low income for these population groups.

Equivalence scales need to take account of changes in household characteristics over time. Over the past 15 years, the number of single-person and sole-parent households increased from 22 per cent to 29 per cent of all households, and the average number of children per family fell. As the average number of people in households falls, average household incomes also tend to fall. If average household size falls more for low-income groups than for high-income groups, then disparities between their incomes will apparently widen. Take HES data for average household income. Real household income fell by 7.8 per cent between $1975-76$ and 1984, and rose by 0.7 per cent between 1984 and 1988-89. At the same time, average household size fell from 3.09 in 1975-76 to 2.84 in 1984 and 2.78 in 1988-89. In fact, adjusting for these changes in household size implies there was no change in real household income per person between the mid-1970s and the mid-1980s, while real household income per person rose by about 2.5 per cent in the second period. Thus, taking account of changes in household size reverses the apparent direction of change. 


\section{The Poverty Standard}

In defining poverty and a 'poverty line', it is common to distinguish between 'absolute' and 'relative' poverty, with absolute poverty lines usually defined as the cost of a minimally adequate basket of goods and services. Most researchers now agree that value judgments necessarily affect the definition of adequacy, and the composition of a minimally adequate basket of goods and services cannot be separated from the social environment in which people live. Consequently, most research is now based on some measure of relative poverty.

As noted by Sen (1983), the common view of poverty is that it has an irreducibly 'absolute' component, which gives the goal of poverty alleviation its moral imperative. But a relative poverty line denotes relative low income, or the lower tail of the income distribution. The constraints imposed by relative low income may or may not be 'acceptable' to the majority in the community (especially if they do not have to experience it). Yet virtually no modern study of poverty tells us whether people living below the poverty line have an unacceptably low standard of living. This does not mean that relative poverty in rich communities is not real, but rather that we need different sorts of research to link demonstrated problems with living standards and the statistical measures of low income commonly used as proxies for poverty.

The use of a relative poverty line implies that the living standards of the poor should keep pace with general community standards (Saunders \& Whiteford, 1989). ${ }^{4}$ This raises the problem of defining average living standards and measuring trends in these standards. In international comparisons, it is common to use fractions (usually 50 per cent) of mean or median survey income as the poverty line. In Australia, the 'Henderson poverty line' used since the late 1960 s is a relative poverty measure, although it is not based on either mean or median survey income. When originally developed, the Henderson measure was a form of 'absolute' poverty line, since it was defined as the basic wage plus child endowment for a couple with two children. This arbitrary definition was justified on the grounds that it produced a standard 'so austere as, we believe, to make it unchallengeable. No one can seriously argue that those we define as poor are not so' (Henderson, Harcourt \& Harper, 1970, quoted in Saunders, 1994).

The Henderson poverty line was again used by the Commission of Inquiry into Poverty in the early 1970 s, and subsequently by researchers and welfare organisations. This required a means of updating it over time. Initially, the line was adjusted according to movements in average weekly earnings, but since the early 1980s it has been updated in line with Household Disposable Income Per Capita (HDIPC) from the National Accounts. Since the Poverty Inquiry Survey in 1973, HDIPC has grown in real terms by around 30 per cent. This means that the statement that the 'poor have got poorer' when based on incomes compared with the

\footnotetext{
It has been argued that the use of a relative poverty line makes it impossible to abolish poverty, since there will always be income inequality. But if relative poverty is defined as some percentage of community incomes, then it is technically possible to raise all incomes above such a line.
} 
Henderson line is simply not correct. In fact, the absolute living standards of those at the poverty line have risen quite substantially.

The Henderson line has the additional complication that household disposable income measured in income surveys does not coincide with HDIPC measured in the National Accounts. The IDS does not include imputed income from owneroccupied housing or the undistributed earnings of superannuation funds. These are included in the National Accounts, and they have risen more rapidly than other income components. As a result, the Henderson poverty line has actually risen faster than either mean or median survey incomes. Thus, the finding that there has been an 'ever-rising tide' of poverty over the 1980 s inevitably reflects the fact that the Henderson poverty line has increased in relative as well as absolute terms. Studies that use a poverty line adjusted only in line with prices (Bradbury \& Doyle, 1992) or one set at 50 per cent of median income (Harding \& Mitchell, 1992) show declining poverty rates over the $1980 \mathrm{~s}^{5}$

Discussion of poverty usually focuses on the number of people or families with incomes below the poverty line, often referred to as the 'poverty headcount'. But the headcount does not tell us whether families are $\$ 100$ or $\$ 2,000$ a year under the poverty line. Moreover, if a government introduced a new payment that increased the incomes of all the poor from $\$ 2,000$ a year below the poverty line to $\$ 100$ a year below the poverty line, then a headcount measure may register no change in poverty rates. One way of dealing with this is to use more than one poverty line. Some researchers have used 80 per cent, 100 per cent and 120 per cent of the Henderson line as measures of people being either 'extremely poor', 'rather poor', or 'near poor'. International research often defines poverty lines as 40 per cent, 50 per cent or 60 per cent of median income. A further option is to calculate the 'poverty gap', either the aggregate difference (as a percentage of GDP) or average difference (in dollars) between families' actual incomes and their respective poverty lines. As well, indices may be used that weight individuals by their distance below the poverty line. This raises a potential problem with those who have artificially low or negative business incomes. Nevertheless, an index of this sort may provide a superior measure, since the poverty gap and the poverty headcount may move in opposite directions.

The choice of a definition of poverty reflects a set of value judgments, some of which unavoidably have arbitrary elements. There appear to be major problems, however, with the Henderson poverty line commonly used in Australia, since it does not provide consistent measures of trends in the number of people with relative low incomes. As noted by Saunders (1991:26): 'The time is perhaps right to consider once again how the poverty line should be set and how the extent of poverty is best measured'.

\footnotetext{
${ }^{5}$ This is in contrast to the US, where the official poverty line is adjusted in line with prices, and the proportion of the population below the line is as it was in the 1970s. In the UK and New Zealand, the extent of poverty has risen compared with a constant real poverty line (UK Department of Social Security, 1994; Stephens, 1995).
} 


\section{Changes Over Time and International Comparisons}

Much academic and public interest in distributional issues is explicitly comparative. We want to know how our current situation compares with the past, and how we compare with other countries. Such comparisons are often used in assessing specific government policies and decisions.

Determining the impact of government is not straightforward. Measured trends in income may be substantially affected by the beginning and end points of any analysis. For example, in analysing trends in income distribution under Australia's Labor government of 1983-96, it is common to start with the 1981-82 IDS, which is the survey closest in time to Labor's accession to office. But that survey was conducted about six months before the election, during which time unemployment increased by around 50 per cent. Using this survey as the base therefore makes the Hawke Government responsible for the rise in unemployment, and also gives it credit for tax cuts and benefit increases introduced by the previous government. The following year may have been a better starting point; but the ABS did not conduct a survey in 1983. Microsimulation data create further problems. The year 1982-83 was an exceptionally bad one for farmers. ${ }^{6}$ This has a substantial impact on trends in median incomes, and on poverty rates calculated by reference to median incomes. In addition, policy changes may have an effect on income distribution only in the very long run, such as the expansion of superannuation coverage and increased school participation rates over the 1980s.

All the problems discussed above may arise with international comparisons. For example, the United Nations Human Development Report (1996) has recently attracted considerable attention, particularly its estimate that Australia has one of the widest dispersions of income of any developed country. But this finding arises because the figures quoted for Australia make no adjustment for household size, while those for many other countries do use equivalence scales. Similarly, Peter Singer (1995) argues that Australia should adopt specific features of the Japanese model on the assumption that Japan is one of the most equal of developed countries. However, Bauer and Mason (1992) show, that the surveys used to assess the distribution of income in Japan exclude all single-person households, and do not include income data for the non-agricultural self-employed sector, which accounts for about 30 per cent of the total population. Other studies in Japan have concluded that its income distribution was much like the US and relatively unequal in the OECD.

To overcome the formidable problems of data and methodological comparability, the Luxembourg Income Study (LIS) database has been established, offering the opportunity to apply the same approach in nearly all analytical areas (O'Higgins et al., 1990). Although it provides the best source of data for international comparisons, it is not perfect. In some countries, the operation of government policies makes precise comparability impossible. For example, in the UK, mortgage tax

\footnotetext{
${ }^{6}$ Income from unincorporated farm enterprises increased in real terms by 766 per cent between 1982 83 and 1989-90. Using a three-year average as the starting point gives a small real fall of around 4 per cent in farm incomes.
} 
relief for home purchasers is paid as a direct subsidy to lending institutions, and does not appear in the data set. Again, in the UK and other countries, assistance to low-income renters is provided through measured cash subsidies, while indirect subsidies effected through reduced rents, as they are in Australia, are excluded.

The fundamental problem with international comparisons is that measured income means different things in different countries. This reflects the fact that most analysis is restricted to cash disposable income, as defined in Figure 1. In a single year accounting period, taxes and social security contributions, which are much higher in most developed countries than in Australia, are treated as a 'burden'. Middle-income families in larger welfare states are apparently worse-off than similar families in smaller welfare states, because their measured tax liabilities are higher, while the benefits accruing to middle-income households in large welfare states are not counted because they mainly arise as future entitlements. Thus, using a relative measure of poverty will result in lower poverty in large welfare states, not because the poor are absolutely worse-off, but because the median is artificially lowered.

In Australia, in contrast, the processes of redistribution between income groups (targeting) and redistribution across the life-cycle have been substantially separated. More of the redistribution across the life-cycle in Australia is effected through private means, including endowment insurance, home purchase, superannuation and other forms of savings. The costs of these forms of savings are not included in the standard framework summarised in Figure 1, because they are arranged privately. In contrast, the costs of savings (redistribution across the life-cycle) associated with state pensions are included in the standard approach, because they are financed from taxes and social security contributions. Similarly, the exclusion of imputed income from owner-occupied housing from most international comparisons reinforces the impression of higher inequality in small welfare states. The standard framework systematically makes high-taxing welfare states look more equal than low-taxing countries, such as Australia.

\section{Conclusion}

For many of these issues, there is no single technically correct answer. The choice of the unit assumed to share income, the choice of equivalence scales, and the choice of low-income standard are ultimately arbitrary in the sense that there can be good reasons for making different choices. In contrast, the comprehensiveness of the income measure is of fundamental importance. Choice of a different measures can be justified by reference to the objectives of specific studies, but it is important to qualify the conclusions drawn from incomplete measures.

Research results will differ significantly depending on the technical choices made. For example, Whiteford and Kennedy (1995) estimate that the proportion of older Australians (over age-pension age) with relatively low cash disposable in-

\footnotetext{
${ }^{7}$ See Whiteford (1995) and Stählberg (1985) for more detailed discussion. 8

This does not mean that all choices are equally valid: there are specific equivalence scales, for example, that differ markedly from the consensus of this research.
} 
comes varied between 5.5 per cent and 58.8 per cent, depending on the choice of income standards (40 per cent, 50 per cent or 60 per cent of the mean) and equivalence scales. If the one income standard ( 50 per cent of the mean) is used, then relative low income could still vary between 14 per cent and 37 per cent in line with differing equivalence scales, with the 'baseline' equivalence scale used giving an estimate of 30 per cent. Using the same equivalence scales and standard 150 per cent of mean final income), but broadening the income concept to incorporate noncash health, education and housing benefits and imputed income from owneroccupied housing, would reduce the extent of relative low income from 30 per cent to 4.9 per cent. If the poverty line used had been based on percentages of the median, then all these estimates would fall. Moreover, Australia's international ranking changes enormously depending on the measure of resources used. On the basis of cash disposable income, relative poverty among older Australians is three times higher than in Germany; adding government services and imputed income from owner-occupied housing reduces the Australian poverty rate to about 80 per cent of the (also reduced) German' poverty level (Whiteford \& Kennedy, 1995).

Table 1

Comparison of measures of inequality in Australia, 1993-94 Ratio of share of richest quintile to poorest quintile (Q5/Q1)

\begin{tabular}{|lcc|}
\hline Measure of Resources & Q5/Q1 & Q5/Q1 per person \\
\hline 1. Private income & 117.7 & 58.9 \\
2. Gross income & 10.6 & 5.3 \\
3. Disposable income & 8.0 & 4.0 \\
4. Disposable income plus & 5.1 & 2.5 \\
indirect benefits & & \\
5. Final income & 5.3 & 2.64 \\
6. Expenditure & 3.3 & 1.62 \\
7. 'Final expenditure' & 2.6 & 1.32 \\
\hline
\end{tabular}

Note: Private income is from market sources; gross income is private income plus cash benefits; disposable income is gross income minus direct taxes; the next concept adds government spending on health, education and other services; final income then subtracts indirect taxes; expenditure is current spending on commodities and services; final expenditure is current expenditure plus indirect benefits and minus indirect taxes.

Source: Calculated from ABS (1996a).

Similarly, Table 1 shows the effects of using differing measures of resources on estimated inequality. The inequality measure is the ratio of the average income (or share) of the richest 20 per cent of the population to the average income of the poorest quintile. Moving from private or market income to take account of government cash benefits, then direct taxes, then non-cash benefits and indirect taxes, narrows the ratio appreciably. Taking account of household size halves the inequality measure, and has a more significant impact than any form of government policy 
except the provision of social security benefits. Moving from income- to expenditure-based measures of living standards further reduces this measure of inequality.

Most public understanding of the nature of poverty and income inequality in contemporary Australia is highly dependent on technical choices made in analysing statistics on income distribution. The variability of research results suggests that considerable caution should be exercised in reaching firm conclusions about income distribution issues. This does not mean that it is impossible to reach firm conclusions. If studies undertake detailed analysis of the sensitivity of results to technical choices, underlying similarities in trends or differences may be identified. If the direction of change or the direction of difference remains the same under all possible technical choices, then it is highly probable that the trend or difference is real. This suggests, however, that we may have to be content with broad or general conclusions, rather than the implausibly precise claims that are usually made.

\section{References}

Australian Bureau of Statistics (ABS) (1987, 1992, 1996a), The Effects of Government Benefits and Taxes and Household Income, Canberra (Cat. No. 6537.0).

- (1996b), A Provisional Framework for Household Income, Consumption, Saving and Wealth, Canberra (Cat. No. 6549.0).

Bauer, J. \& A. Mason (1992), 'The Distribution of Income and Wealth in Japan', Review of Income and Wealth 38(4): 403-28.

Bradbury, B. \& J. Doyle (1992), Family Incomes and Economic Growth, Social Policy Research Centre, University of New South Wales, Sydney (Reports and Proceedings No. 102).

Creedy, J. (1994), 'Statics and Dynamics of Income Distribution: An Introductory Survey', Australian Economic Review, 4th Quarter: 51-71.

Falkingham, J. \& A. Harding (1996), Poverty Alleviation versus Social Insurance Systems: A Comparison of Lifetime Redistribution, NATSEM, University of Canberra (Discussion Paper No. 12).

Gregory, R. (1993), 'Aspects of Australian and US Living Standards: The Disappointing Decades 1970-1990', Economic Record 69 (204): 61-76.

- \& B. Hunter (1995), The Macro Economy and the Growth of Ghettos and Urban Poverty in Australia, Centre for Economic Policy Research, Australian National University, Canberra (Discussion Paper No. 325).

Harding, A. (1982), 'An Introduction to the Social Wage', Social Security Joumal, December: 13-21.

(1993), 'Lifetime vs Annual Tax-Transfer Incidence: How Much Less Progressive?', Economic Record 69 (205): 179-92.

\footnotetext{
9

9 The measure of 'final expenditure' should be regarded as illustrative, as it simply involves adding government-provided consumption (non-cash benefits minus indirect taxes) to private expenditure on commodities and services. It should also be noted that the adjustment for household size does not take account of economies of scale or the lower needs of children, thus tending to overstate the level of equality of consumption and income.
} 
- (1995), 'The Distributional Impact of Social Wage Infrastructure in 1994', paper presented to the Public Sector Research Centre Seminar on Infrastructure: Meeting Australia's Economic and Social Needs, Sydney (31 March).

- \& D. Mitchell (1992), 'The Efficiency and Effectiveness of the Tax-Transfer System in the 1980s', Australian Tax Forum 9(3): 277-304.

Henderson, R., A. Harcourt \& R. Harper (1970), People in Poverty: A Melbourne Survey, Cheshire, Melbourne.

O'Higgins, M., G. Schmaus \& G. Stephenson (1990), 'Income Distribution and Redistribution: A Microdata Analysis for Seven Countries', pp. 20-56 in T. Smeeding, M. O'Higgins \& L. Rainwater (eds), Poverty, Inequality, and Income Distribution on Comparative Perspective, Harvester Wheatsheaf, Hemel Hempstead.

Saunders, P. (1990), Employment Growth and Poverty: An Analysis of Australian Experience, 1983. 1990, Social Policy Research Centre, University of New South Wales (Discussion Paper No. 24).

- (1994), Welfare and Inequality: National and International Perspectives on the Australian Welfare State, Cambridge University Press, Melbourne.

—_ \& P. Whiteford (1989), Measuring Poverty: A Review of the Issues, Economic Planning Advisory Council, Canberra (Discussion Paper 89/11).

Sen, A. (1983), 'Poor, relatively speaking', Oxford Economic Papers 35: 153-69.

Singer, P. (1995), 'Inequality', Australian Business Monthly, February: 5-9.

Smeeding, T., P. Saunders, J. Coder, S. Jenkins, J. Fritzell, A. Hagenaars, R. Hauser \& M. Wolfson (1992), Noncash Income, Living Standands and Inequality: Evidence from the Luxembourg Income Study, CEPS/INSTEAD, Luxembourg.

Stählberg, A-C. (1985), On Misleading Income Comparisons between Societies with Social Insurance Sectors of Different Sizes, Swedish Institute for Social Research, Stockholm (Discussion Paper 18/1985).

Stephens, R. (1995), 'Measuring Poverty in New Zealand, 1984-93', paper presented to conference on Social Policy and the Challenges of Social Change, Social Policy Research Centre, University of New South Wales, Sydney (July).

Travers, P. \& S. Richardson (1993), Living Decently: Material Well-Being in Australia, Oxford University Press, Melbourne.

United Kingdom, Department of Social Security (1994), Households Below Average Income: A Statistical Analysis 1979-1991/92, HMSO, London.

United Nations (1996), Human Development Report 1996, Oxford University Press, Oxford.

Whiteford, P. (1985), A Family's Needs: Equivalence Scales, Poverty and Social Security, Development Division, Department of Social Security, Canberra (Research Paper No. 27).

- (1995), 'Is Australia Particularly Unequal?', paper presented to conference on Social Policy and the Challenges of Social Change, Social Policy Research Centre, University of New South Wales, Sydney (July).

- \& S. Kennedy (1995), Incomes and Living Standards of Older People, UK Department of Social Security, HMSO, London (Research Report No. 34).

Yates, J. (1991), Australia's Owner-Occupied Housing Wealth and Its Impact on Income Distribution, Social Policy Research Centre, University of New South Wales (Reports and Proceedings No. 92). 